\title{
LA PRIMERA SENTENCIA DE AMPARO EN MÉXICO (UN ANTECEDENTE DE HISTORIA CONSTITUCIONAL)
}

\author{
José F. Palomino Manchego*
}

\begin{abstract}
Resumen
Se da cuenta de la primera sentencia de Amparo en la historia del Derecho Constitucional, que fuera pronunciada en México, y se analizan las tres etapas sucesivas por las que ha pasado el Juicio de Amparo en el contexto histórico del siglo XIX, así como su subsecuente desarrollo y regulación.
\end{abstract}

Palabras clave: Constitución - Juicio de Amparo - Derechos individuales -Tutela de la libertad personal.

\begin{abstract}
We realize the first Amparo judgement in the history of the constitutional law, which was pronounced in Mexico, and we also analyze the three successive periods where it passed this Amparo proceedings in the historic context of the XIX century, as it subsecuent development and regulation.
\end{abstract}

Key words: Constitution - Amparo proceedings - Individual Rights Protection of personal freedom.

Sumario

I.- Antecedentes y situación actual del Juicio de Amparo. II.- Análisis de la sentencia. III.- A modo de conclusión. IV.- Apéndice.

\section{ANTECEDENTES Y SITUACIÓN ACTUAL DEL JUICIO DE AMPARO}

No cabe duda que sobre el "castizo, evocador y legendario" Juicio de Amparo mexicano, tildado de esa manera por Felipe TENA RAMírEZ, se han escrito ríos de tinta desde el siglo XIX hasta nuestros días, estudiándose así profusamente a la "máxima institución procesal" habida en México, como lo ha reconocido más de pronto Héctor FIX-ZAMUDIO. En esta oportunidad daremos cuenta de la primera sentencia de Amparo - casi todos los autores coinciden en

\footnotetext{
* Director de la Escuela Académico Profesional de Derecho de la Universidad Nacional Mayor de San Marcos. Profesor de Pregrado y Posgrado de las universidades Nacional Mayor de San Marcos, de Lima, Universidad Inca Garcilaso de la Vega, Universidad San Martín de Porres y de la Academia de la Magistratura. Secretario Ejecutivo del Instituto Iberoamericano de Derecho Constitucional (Sección Peruana). Miembro Asociado de la Académie Internationale de Droit Comparé. Miembro de la Asociación Argentina de Derecho Constitucional.
} 
José F. Palomino Manchego - La primera sentencia de amparo en México

(Un antecedente de historia constitucional)

este hecho significativo - que fue pronunciada el 13 de agosto de 1848 por el Juzgado del Distrito del Estado (reconocido como tal por la Constitución de 1824) de San Luis Potosí, importante centro minero de la etapa virreinal, fundado en 1576. Años atrás, de 1841 a 1847, el Estado había sufrido diversas incursiones de indios bárbaros; además, en su territorio se llevaron a cabo varias revoluciones. Para nuestros propósitos, es útil dar cuenta de estos hechos episódicos.

Empero, nuevas pesquisas realizadas en el Archivo General de la Nación demuestran que el primer Amparo - ¿supuestos de Amparo? - lo sustanció ante la Suprema Corte el periodista y editor de El Monitor Republicano, Vicente GARCÍA TORRES en 1847, ante la orden de aprehensión expedida por el general en jefe del Ejército de Oriente, Antonio LÓPEZ DE SANTA ANNA, quien había vulnerado así, la libertad de imprenta ${ }^{1}$ en una etapa muy convulsionada debido a la invasión de Estados Unidos.

Sin embargo, no resulta ocioso recordar las tres etapas sucesivas por las que ha pasado el Juicio de Amparo, ${ }^{2}$ como institución de vanguardia, para poder ubicar mejor a la primera sentencia dentro del contexto histórico del siglo XIX:

a) El Juicio de Amparo surgió con este nombre en el artículo 8 de la Constitución del Estado de Yucatán (entidad federativa) sancionada el 31 de marzo de 1841, como instrumento procesal para proteger a los gobernados (ciudadanos) frente a los actos y leyes de las autoridades. La Carta yucateca tuvo su origen en el proyecto suscrito el 23 de diciembre de 1840 por los diputados Manuel Crescencio REjón (1799-1849), Pedro C. PÉREZ y Darío ESCALANTE, acentuándose el influjo del primero de los nombrados, a quien se ha considerado con razón como el "padre o mentor principal del Amparo".

b) En el ámbito nacional, el Juicio de Amparo fue fincado en el artículo 25 del Acta Constitutiva de Reformas de 18 de mayo de 1847, discutida por el Congreso en corto tiempo (del 5 de abril al 14 de mayo) ${ }^{3}$, que tomó como fuente de inspiración el artículo 19 del proyecto ${ }^{4}$ - voto

1 Para mayor detalle, vid. Manuel GONZÁlez OropezA: «Los orígenes del control jurisdiccional de la Constitución y de los derechos humanos», Comisión Nacional de los Derechos Humanos, México, D.F., 2003, págs. 233-279. El autor menciona además otros antecedentes apoyado en fuentes históricas.

2 Entre otros, vid. José Luis SOBERANES FERNÁNDEZ: «Antecedentes del Amparo en México», en Ius et Praxis, n 14, Lima, 1989, págs. 61-82. Más de pronto, José Luis SOBERANES FERNÁNDEZ y Faustino José MARTínEZ MARTínEZ: «Apuntes para la historia del Juicio de Amparo», Editorial Porrúa, México, D.F., 2002.

3 Para un estudio pormenorizado del Acta de Reforma que se publicó el 28 de mayo de 1847 en el Diario del Gobierno, vid. el libro La reforma del Estado Federal, Instituto de Investigaciones Jurídicas de la UNAM, México, D.F., 1998; con Estudio introductorio y compilación a cargo de Manuel GONZÁLEZ OROPEZA.

4 Reza literalmente el artículo 19: "Los tribunales de la Federación ampararán á cualquier habitante de la República en el ejercicio y conservación de los derechos que le concedan esta Constitución y las leyes 
José F. Palomino Manchego - La primera sentencia de amparo en México

(Un antecedente de historia constitucional)

particular - redactado por el jurista y orador político jalisciense Mariano OTERO (1817-1850), a fuer, segundo padre del Juicio de Amparo. Nace así la fórmula doctrinaria conocida con el nombre de "fórmula Otero", cuyo propósito es señalar los efectos particulares - en tanto afecte los derechos del solicitante - del fallo del Amparo, en el supuesto en que se impugnara la inconstitucionalidad de una ley. El carácter casi sacramental de la "fórmula Otero", como advierte FIX-ZAMUDIO, se reitera posteriormente en el artículo 102 de la Carta Federal de 1857, y en el artículo 107, fracción II, de la Constitución de 1917. Y, producto de los debates constituyentes de 1856-1857, el modelo original del Juicio de Amparo se plasma, en definitiva, en los artículos 101 y 102 de la Carta Federal promulgada el 5 de febrero de 1857, la que fue calificada por Daniel Cosío VILLEGAS como "una marca señalada de la historia patria" 5 .

De manera paralela, luego de haberse dado en orden cronológico el Proyecto de Ley Constitucional de garantías individuales de 29 de enero de 1849, el Proyecto de Ley de Amparo de 3 de febrero de 1849 y el Proyecto de Ley Reglamentaria del artículo 25 del Acta de Reformas de febrero de 1852, el 30 de noviembre de 1861 se expidió la primera Ley de Amparo, ${ }^{6}$ con lo cual se reglamentaron, como lo sugirió Mariano OTERO, los artículos 101 y 102 antes citados, percibiéndose en su redacción una combinación del procedimiento civil tradicional, y el intento de captar el espíritu de la revisión judicial norteamericana (judicial review of legislation). A ella le han seguido la Ley Orgánica de Amparo de 20 de enero de 1869, la Ley Orgánica de Amparo de 14 de diciembre de 1882, el Código de Procedimientos Federales de 6 de octubre de 1897, el Código Federal de Procedimientos Civiles de 26 de diciembre de 1908, la Ley Reglamentaria de los artículos 103 y 104 de la Constitución Federal de 18 de octubre de 1919 y la Ley de Amparo vigente de 1936, con las reformas correspondientes. En la actualidad se encuentra en debate el Proyecto de la Nueva Ley de Amparo de $1^{\circ}$ de marzo del año 2001, reglamentaria de los artículos 103 y 107 de la Constitución Federal de 5 de febrero de 1917, elaborado por el Pleno de la Suprema Corte de Justicia de la Nación y antecedido por una prolija Exposición de Motivos.

constitucionales, contra todo ataque de los Poderes Legislativo y Ejecutivo, ya de la Federación, ya de los Estados, limitándose dichos tribunales á impartir su protección en el caso particular sobre que verse el proceso, sin hacer ninguna declaración general respecto de ley ó del acto que lo motivare".

5 Cfr. Daniel Cosío Villegas: «La Constitución de 1857 y sus críticos», 2a . edición, Secretaría de Educación Pública, México, D.F., 1973, pág. 9. Hay 4a. edición por el Fondo de Cultura Económica, México, D.F., 1998, con Prólogo de Andrés LIRA.

6 Para tal fin, vid. José BARRAGÁn BARRAGÁn: «Primera Ley de Amparo de 1861», UNAM, México, D.F., 1980. Recuerda el autor (págs. 27-34), como antecedente, el Proyecto de Ley de Amparo de 1857 del diputado Domingo María PÉREZ FERNÁNDEZ, presentado en la sesión del día 16 de noviembre de 1857, poco menos que ignorado por la doctrina. 
José F. Palomino Manchego - La primera sentencia de amparo en México

(Un antecedente de historia constitucional)

A propósito, conviene recordar que las fuentes foráneas (influencia externa) para dar nacimiento al Amparo, fueron:

a) La Constitución Federal de Estados Unidos de 1787 (art. VI) y el Habeas Corpus angloamericano.

b) La influencia española en tanto que la voz "Amparo" proviene de antecedentes castellanos y aragoneses, en especial de los fueros (recuérdese que México antes de su independencia pertenecía al Virreinato - era virreinal - de la Nueva España) ${ }^{7}$.

c) El influjo francés a través de la Declaración de Derechos del Hombre y del Ciudadano de 1789 (las constituciones mexicanas, desde sus inicios emplean el término "garantías individuales"), y del Senado Conservador de la Constitución francesa del año VIII (encargado de pronunciarse sobre la inconstitucionalidad de los actos que le fueran sometidos por el Tribunado o por el gobierno, según las ideas de Emmanuel Joseph SIEYÈs (1748-1836) ${ }^{8}$, verdadero ideólogo de la Revolución francesa) a través del denominado Supremo Poder Conservador introducido en las leyes constitucionales mexicanas de 1836, y además algunos elementos de la casación francesa. A lo anteriormente expuesto, añádase la obra clásica de Alexis de Tocqueville (1805-1859) intitulada De la democracia en América, ${ }^{9}$ libro de cabecera - publicado en París en 1835, y al año siguiente, 1836, traducido al español - no solo para los políticos mexicanos, tales como Manuel Crescencio GARCía REJÓN y ALCALÁ y Mariano OTERO, sino también para los hombres que forjaron la independencia en Hispanoamérica luchando contra el dominio español.

De otro lado, resulta preciso señalar que en las actuales circunstancias el Juicio de Amparo (verdadera y auténtica federación de instrumentos procesales, en palabras de FIX-ZAMUDIO, o también, instrumento procesal de múltiples rostros), catalogado como la institución más prestigiada del Derecho mexicano, cumple en dicho país las siguientes funciones proteccionistas y polivalentes, a diferencia de otros instrumentos procesales que operan en los diversos ordenamientos constitucionales de Iberoamérica ${ }^{10}$ :

7 Como antecedentes, vid., el libro esclarecedor de Andrés LIRA GonZÁlEZ: «El Amparo colonial y el Juicio de Amparo mexicano (Antecedentes novohispanos del Juicio de Amparo)», F.C.E., México, D.F., 1972. Antecede Prólogo de Alfonso NORIEGA CANTÚ.

8 Al respecto, vid. Escritos políticos de Sieyès, F.C.E., México, D.F., 1993. Introducción, estudio preliminar y compilación de David PANTOJA MORÁN. Y más de pronto, del mismo autor, Escritos y discursos de la Revolución, Centro de Estudios Constitucionales, Madrid, 2007. Edición, traducción del francés y notas de Ramón Máiz.

9 Y, como complemento, es básico consultar a Alexis DE TOCQUEVILLE: «Discursos y escritos políticos», Centro de Estudios Políticos y Constitucionales, Madrid, 2005. Edición, estudio preliminar y traducción del francés de Antonio Hermosa ANDÚJAR.

10 A efectos meramente descriptivos, Adolfo POSADA - para quien el régimen constitucional mexicano es de tipo predominantemente escrito y formalista, codificado, rígido, de carácter expreso y deductivo - denominó 
José F. Palomino Manchego - La primera sentencia de amparo en México

(Un antecedente de historia constitucional)

a) la tutela de la libertad y de la integridad personales (Amparo-libertad) de acuerdo con los lineamientos del Habeas Corpus angloamericano (tal como se presentó en la primera sentencia materia de análisis: el destierro);

b) como medio de impugnación de las disposiciones legales que se estiman contrarias a la Constitución federal, mediante el denominado "Amparo contra leyes";

c) permite también el ataque a la ilegalidad de las resoluciones judiciales tanto de carácter federal como locales, de forma similar al recurso de casación, de ahí que se le ha calificado como "Amparo-casación";

d) se emplea como un medio para combatir resoluciones o actos de autoridades administrativas federales y locales, cuando las controversias respectivas no pueden plantearse ante tribunales administrativos o judiciales ordinarios, y como tal es considerado como un "proceso contencioso-administrativo"; $\mathrm{y}$

e) protege los derechos individuales y colectivos de los campesinos sujetos al régimen de la reforma agraria, de ahí que se le haya calificado como "Amparo social agrario"11.

Tales rasgos definitorios le han dado al Juicio de Amparo mexicano una presencia activa, y sobre todo, protección efectiva y seguridad a los justiciables. ${ }^{12}$ De ahí que se diga que ha sido parte de la conciencia de la

al Juicio de Amparo "complemento muy importante" del régimen jurídico de la personalidad. Cfr. Adolfo Posada: Instituciones de los pueblos hispano-americanos, Hijos de Reus, Editores, Madrid, 1900, pág. 106.

11 Tal como lo ha precisado Héctor FIX-ZAMUDIO en sus diversos estudios. Entre otros, vid. «Breve introducción al Juicio de Amparo» en su libro del cual hemos tomado valiosos datos Ensayos sobre el Derecho de Amparo, 2a . edición, Editorial Porrúa-UNAM, México, D.F., 1999, págs. 90-91. En el caso peruano, el Amparo se introdujo en nuestro ordenamiento jurídico a través del Decreto Ley $\mathrm{N}^{\circ} 20554$, dado en el Gobierno de facto de Juan Velasco Alvarado:

Artículo 1.- Si un propietario estimare que no ha incurrido en causal de afectación o de declaración de abandono, podrá interponer recurso de Amparo ante el Tribunal Agrario dentro del término de quince días computados a partir de la notificación del correspondiente Decreto Supremo de expropiación o de extinción de dominio, exponiendo los fundamentos de hecho y de derecho, sin cuyo requisito será denegado. La interposición del recurso será puesta en conocimiento del Poder Ejecutivo por intermedio de la Dirección General de Reforma Agraria y Asentamiento Rural, dentro de dos días recibida. Mientras se resuelva el recurso de Amparo, no se interpondrá la demanda de expropiación de las tierras afectadas. Los Decretos Supremos que no sean impugnados dentro del término señalado, causarán ejecutoria. Artículo 2.- La Dirección General de Reforma Agraria y Asentamiento Rural expondrá lo conveniente a nombre del Poder Ejecutivo, remitido al Tribunal Agrario el expediente administrativo original dentro del término de cinco días durante el cual las partes podrán solicitar se las cite para informar oralmente a la visita de la causa lo que deberá realizarse dentro de los ocho días siguientes sin permitir aplazamiento. El Tribunal pronunciará resolución dentro de los seis días siguientes. Si fuera denegado el recurso, la Dirección General de Reforma Agraria y asentamiento Rural interpondrá la demanda de expropiación ante el Juez de Tierras competente. Artículo. 3.- En caso que el propietario o conductor del predio después de interpuesto el recurso de Amparo dejare de pagar los salarios a los trabajadores durante dos semanas consecutivas, la Dirección General de Reforma Agraria y Asentamiento Rural pondrá el hecho en conocimiento del Tribunal Agrario, quien lo considerará como causal de denegatoria del Amparo.

12 Vid. Segundo V. LINARES QUINTANA: «Acción de Amparo (Estudio comparado con el Juicio de Amparo de México y el Mandato de Seguridad de Brasil)», Editorial Bibliográfica Argentina, Buenos Aires, 1960, pág. 39. 
José F. Palomino Manchego - La primera sentencia de amparo en México

(Un antecedente de historia constitucional)

Nación mexicana, siendo su función tuitiva fuente de inspiración, con efectos extraordinarios, para las constituciones en el Derecho Comparado, donde ya se habla de un "Amparo Iberoamericano", tal como se acaba de reafirmar en una reciente publicación. ${ }^{13}$

\section{ANÁLISIS DE LA SENTENCIA}

Dadas las circunstancias de la época, no se puede decir que estamos frente a una verdadera sentencia constitucional: estimativa o desestimativa, es decir, la decisión de un colegiado de jueces que pone término a un proceso. Sin embargo, constituye un esfuerzo para demostrar que la judicatura federal mexicana a mediados del siglo XIX estaba concientizada - así lo demuestra su labor interpretativa - con tan importante instituto procesal: el Juicio de Amparo.

El fondo del asunto era la orden de destierro, que debía dejarse sin efecto a través del Amparo. Se trata, desde luego, de un Amparo-libertad, por cuanto el destierro, que consiste en expulsar a una persona de un lugar o territorio determinado, donde no podrá residir de manera temporal o permanente, se frena con el Habeas Corpus. En el siglo XIX el destierro, como sucedió en México, todavía tenía un signo de naturaleza política. El Derecho Romano reconocía dos instituciones: a) la relegatio y b) la deportatio in insulam, y en la actualidad el Derecho Penal le ha dado otro tipo de características: el confinamiento y la expatriación forzosa.

En lo que atañe a la sentencia sub examine, FERRER MAC-GREGOR sostiene con acierto que posee los elementos que caracterizan el Juicio de Amparo: 1. Quejoso o agraviado: Manuel VERÁSTEGUI. 2. Acto reclamado (acto lesivo): la orden de destierro violatoria de garantías (entiéndase derechos) individuales. 3. Fundamento del Amparo: el artículo 25 del Acta Constitutiva y de Reformas. 4. Autoridad responsable (agresor): el Gobernador del Estado. 5. Otorgamiento del Amparo: declarar la protección solicitada teniendo como efectos el no destierro sin previo juicio de autoridad competente. 6. Informe justificado: el alegato del Gobernador del Estado, en el sentido de que no había sido reglamentado el modo y términos que disponía el artículo 25 del Acta Constitutiva y de Reformas. 7. Notificación de la sentencia: al quejoso, expidiéndole copia testimoniada si la pidiere, y al supremo gobierno del

\footnotetext{
13 Nos estamos refiriendo al colectivo, de superlativa importancia, coordinado por Héctor FIX-ZAMUDIO y Eduardo FERRER MAC-GREGOR: «El Derecho de Amparo en el mundo», UNAM-Editorial Porrúa, S.A.Konrad-Adenauer-Stiftung, México, D.F., 2006.
} 
José F. Palomino Manchego - La primera sentencia de amparo en México

(Un antecedente de historia constitucional)

Estado para el debido cumplimiento (ejecución) del fallo. 8. Apercibimiento por incumplimiento: uso de los recursos que la ley señala para hacer cumplir lo ordenado. ${ }^{14}$

En línea con las anteriores consideraciones, si bien el objeto de estudio es la sentencia, lo cierto es que no se han conocido las otras piezas del expediente, tales como:

a) el texto de la demanda de Amparo de Manuel VerásteguI,

b) el informe o "comunicación" que dirigió al Juzgado de Distrito el Gobernador del Estado, Julián DE LOS REYES,

c) el texto del "dictamen" que rindió el asesor; tampoco se conoce el nombre del asesor, presumiendo que sea un abogado competente para conocer los efectos y alcances del artículo 25 del Acta Constitutiva y de Reformas, ${ }^{15}$ en el cual se basó para hacer el razonamiento,

d) si la sentencia de Amparo parece firmada por Pedro ZÁMANO, resulta que en las numerosas referencias que se tienen de dicho personaje, antes y después de la sentencia, su apellido aparece escrito como SÁMANO,

e) se ignora quién era el juez titular del Juzgado de Distrito cuando se dictó la sentencia de Amparo suscrita por "Pedro ZÁmANO, primer suplente del Juzgado de Distrito en actual ejercicio por ausencia del propietario",

f) por cuanto Manuel DE ARRIOLA, seguramente secretario del Juzgado de Distrito - aun cuando no se dice que lo fuera - en 1844, cinco años antes de la sentencia, fue uno de los que suscribieron el acta de instalación de la "Sociedad Patriótica Potosina", y que fue "Escribano Público Nacional" desde 1843 hasta 1857,

g) de otro lado, Pedro SÁmANo fue aspirante al gobierno del Estado en la elección de 1848, y su contrincante fue Julián de los Reyes, empero, resultó entonces electo Ramón Adame, y

${ }_{14}$ Cfr. el excelente libro de Eduardo FERRER MAC-GREGOR: «La acción constitucional de Amparo en México y España», 3a. edición, Editorial Porrúa, S.A., México, D.F., 2002, pág. 84. Incluye, además, la sentencia bajo comentario en las págs. 83-84. Antecede Prólogo de Héctor FIX-ZAMUDIO. También vid., entre otros, Carlos ARELlANO GARCÍA: «El Juicio de Amparo», 2a . edición, Editorial Porrúa, S.A., México, D.F., 1983, págs. 120-122.

15 El Acta Constitutiva y de Reformas a la Constitución Federal de 1824 fue sancionada por el Congreso Extraordinario Constituyente de los Estados Unidos Mexicanos el 18 de mayo de 1847, jurada y promulgada el 21 del mismo año. El famoso artículo 25, sin desmerecer por su contenido a los artículos 5, 22, 23 y 24, apuntaba lo siguiente: "Los Tribunales de la Federación ampararán a cualquiera habitante de la República en el ejercicio y conservación de los derechos que le concedan esta Constitución y las leyes constitucionales, contra todo ataque de los Poderes Legislativo y Ejecutivo, ya de la Federación, ya de los Estados; limitándose dichos tribunales [de la Federación] a impartir su protección en el caso particular sobre que verse el proceso, sin hacer ninguna declaración general respecto de la ley ó del acto que lo motivare". Al respecto, vid. Felipe TenA RAMíreZ: «Leyes fundamentales de México (1808-1999)», 22ª . edición actualizada, Editorial Porrúa, S.A., México, D.F., 1999, pág. 475. 
José F. Palomino Manchego - La primera sentencia de amparo en México

(Un antecedente de historia constitucional)

h) Manuel VerÁstegui, principal autor y director de "La Revolución de la Sierra Gorda", tenía celebrado un compromiso con Eleuterio QUIROZ para invadir el Estado de San Luis Potosí hasta llegar a su capital, y colocar en el gobierno a Ramón ADAME o a Pedro SÁmANO.

Así, en suma, las circunstancias antes descritas demuestran de manera clara la amistad íntima y los estrechos intereses en política que tuvieron entre sí Pedro SÁmANO y Manuel VERÁSTEGUI, muy poco antes de que este último solicitara la protección de la justicia federal, Amparo que le tocó fallar a Pedro SÁMANO, reciente rival en política del gobernador Julián DE LOS REYES ${ }^{16}$.

\section{A MODO DE CONCLUSIÓN}

Resulta interesante ver cómo los operadores judiciales en el siglo XIX iban adquiriendo experiencia, de tal forma que el Juicio de Amparo empezaba a tomar cuerpo en el Estado Federal de México, producto de coyunturas políticas y constantes agresiones a los derechos constitucionales de las personas. Así, el Juicio de Amparo, desde la etapa in status nascendi, ya cumplía una tarea noble y educadora que con el transcurso del tiempo han sabido respetar y admirar los gobernantes y gobernados.

Por las razones anotadas con antelación, el Amparo es, en esencia, un método, un procedimiento, un remedio constitucional; por su forma [es] juicio; por su objeto, en cierto modo, recurso que lleva por finalidad restituir al sujeto quejoso en el goce de las garantías constitucionales [entiéndase derechos fundamentales] cuando por ley o acto cualquiera de autoridad se le lesionan; o que la autoridad federal o las de los Estados federados vuelvan a sus respectivas órbitas, cuando mutuamente se invadan ${ }^{17}$.

\section{APÉNDICE}

San Luis Potosí, agosto 13 de 1848. Visto el antecedente, Dictamen y teniendo presente que el artículo 25 de la Acta de Reformas impone al Juzgado a mi cargo la obligación de amparar a cualquier ciudadano contra los ataques violentos, ya sea de los Supremos Poderes de la Nación, ya de los Estados; que la circunstancia de no haberse reglamentado el modo y términos en que

\footnotetext{
${ }_{16}$ Tal y conforme lo sostiene José Francisco PEDRAZA MONTES: «La primera sentencia de Amparo en México», en Órgano informativo del Poder Judicial de la Federación, Suprema Corte de Justicia de la Nación, San Luis Potosí, S.L.P., 13 de agosto de 1999, págs. 2-3. El texto de la sentencia que va como apéndice al presente ensayo se ha tomado literalmente de dicho Órgano informativo.

17 Así lo ha plasmado con propiedad RODOLFO REYES en su libro: «Ante el momento constituyente (Experiencias y ejemplos americanos)», Compañía Ibero-Americana de Publicaciones, S.A., Madrid-Barcelona-Buenos Aires, 1931, pág. 55.
} 
José F. Palomino Manchego - La primera sentencia de amparo en México

(Un antecedente de historia constitucional)

tal protección debe dispensarse, no es ni puede ser obstáculo para cumplir con ese sagrado deber, porque a nadie puede ocultarse el modo de sustanciar un expediente y que, de no dar cumplimiento al citado Artículo, resultaría una contravención del objeto y fin que los legisladores se propusieron, no menos que una notable infracción; que inconcusamente haría responsable al que la cometiera; que una ley desde el momento que se publica debe ser obligatoria; no expresándose en ella lo contrario, como dice muy bien el asesor, y por lo mismo no se ha podido ni se puede dejar de cumplir con la referida disposición Constitucional, a pesar de las razones que expresa el Sr. Gobernador del Estado en la comunicación que dirigió a este Juzgado el 4 del corriente por conducto de su secretaria, por no ser suficientes para no observar lo que manda la Ley con objeto de proteger las garantías individuales, y siendo como es cierto que el mismo Sr. Gobernador expidió contra D. Manuel Verástegui la orden de destierro que motivó el ocurso que ha dado lugar a la formación de las antecedentes actuaciones, contraviniendo lo dispuesto por el Supremo Gobierno de la Unión a consecuencia de la Ley de 24 de abril del corriente año, y cometiendo un verdadero ataque a las garantías individuales que deben respetarse siempre por cualquier autoridad, por estar afianzadas en la Constitución y ser esto conforme al buen orden y comunal provecho de la sociedad, por tales fundamentos y demás que se contienen en el precitado dictamen a que me refiero, se declara que este Juzgado dispensa a D. Manuel Verástegui la protección que solicita, en conformidad de lo dispuesto en el repetido artículo 25 del Acta de Reformas para que no pueda ser desterrado del Estado, sin que preceda la formación del juicio y pronunciamiento del fallo por la autoridad judicial a que exclusivamente corresponde por la Constitución; debiendo quedar entre tanto en el pleno uso de los derechos y libertad que la misma Carta Fundamental le concede como ciudadano mexicano. Comuníquese esta disposición al interesado para su inteligencia, dándole copia testimoniada de ella si la pidiera.

Hágase igual comunicación por medio de la correspondiente nota al Supremo Gobierno del Estado, para el debido acatamiento de este fallo y sus efectos, manifestándole a la vez que el Juzgado en manera alguna espera se le obligue a usar de los recursos que la Ley ha puesto en sus manos para hacer respetar y cumplir sus disposiciones, estando como se haya dispuesto a conservar la dignidad de este Tribunal, y hacer que sus fallos sean debidamente respetados, y dése cuenta con todo el Supremo Gobierno de la Unión para los efectos a que hubiere lugar. El Señor Pedro Zámano, primer suplente del Juzgado de Distrito en el actual ejercicio por ausencia del propietario. Así lo decretó, mandó y firmó por ante mí, de que doy fe. Pedro Zámano. Manuel de Arriola. 